\section{Zur Auswahl der Dokumente und Illustrationen}

Die Illustrationen wurden nach zwei Hauptgesichtspunkten ausgewählt. Zum einen sollen die historische Entwicklung der äußeren Erscheinungsform der Lieferungsromane und Änderungen in der Technik und Qualität dokumentiert werden. Zum anderen geht es um die Veranschaulichung besonders aufschlußreicher bzw. typischer Sujets und Darstellungsformen. Die sonstigen Dokumente sollen vor allem Einblicke in die Werbestrategien und die Binnenkommunikation der Branche vermitteln.

Im nachhinein betrachtet haben wir zwei naheliegenden Versuchungen nicht ganz widerstehen können: Die Freude am naiven Charme der farbigen Lithographien aus den fünfziger, sechziger und siebziger Jahren des vorigen Jahrhunderts führte zu einer gewissen Konzentration auf diese Phase. Nachgegeben haben wir in einigen Fällen auch dem Interesse des Sammlers an besonders seltenen oder kuriosen Beispielen.

Insgesamt waren wir bemüht, aus der Vielzahl häufig belangloser Illustrationen solche auszuwählen, die uns aus den unterschiedlichsten Gründen besonders aussagekräftig erschienen. Insofern vermittelt unser Abbildungsteil einen abwechslungsreicheren und dramatischeren Eindruck als ihn die Illustrationen eines einzelnen Romans bieten würden.

Die Nummernangaben beziehen sich auf die Bibliographie; ungeläufige Abkürzungen sind am Beginn der Bibliographie aufgeschlüsselt. 

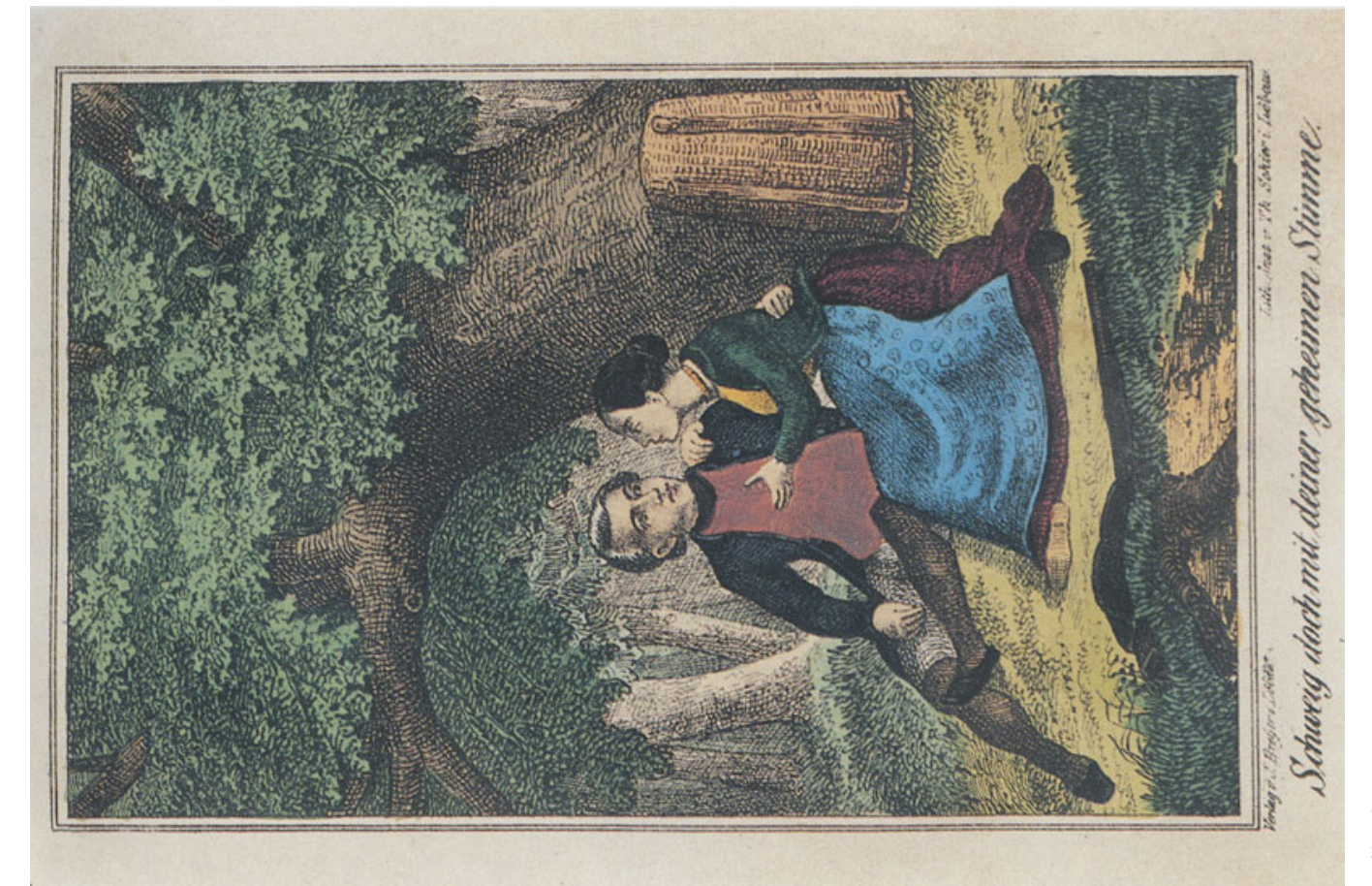

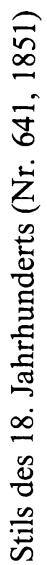

\begin{tabular}{l}
$i$ \\
\multirow{8}{*}{}
\end{tabular}
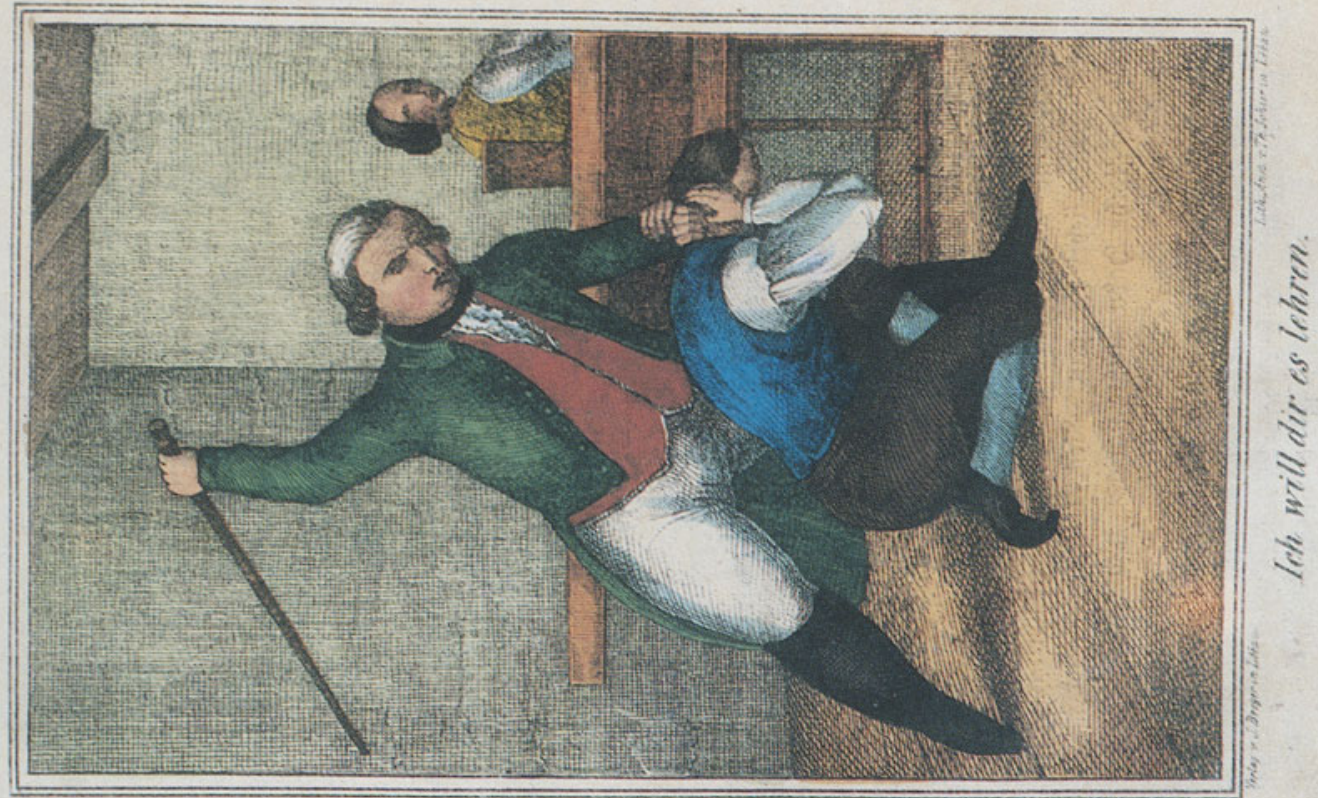

สำ 

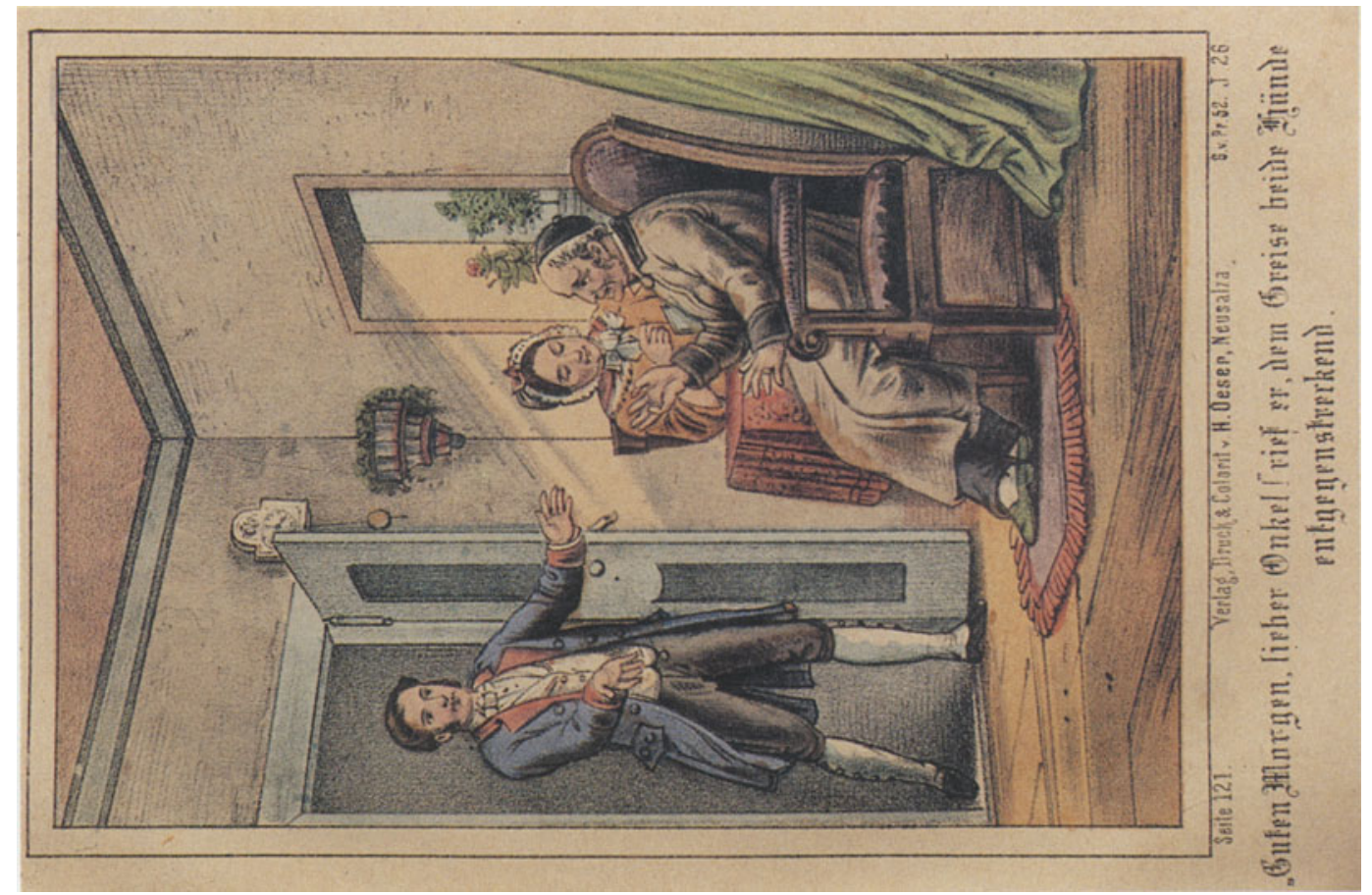

$\stackrel{1}{*}$
$\stackrel{7}{*}$
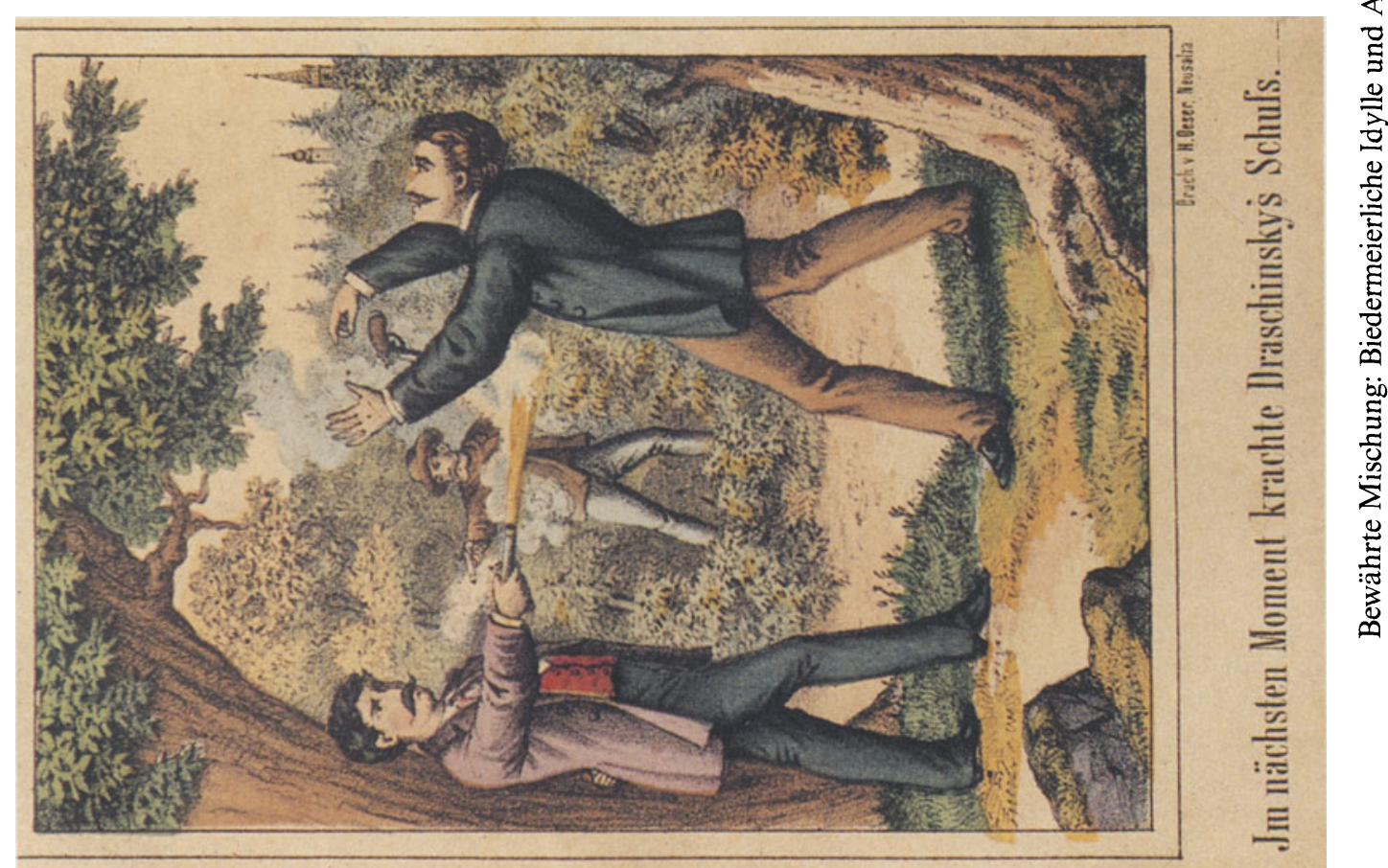

$\stackrel{+}{*}$
$\stackrel{0}{*}$ 

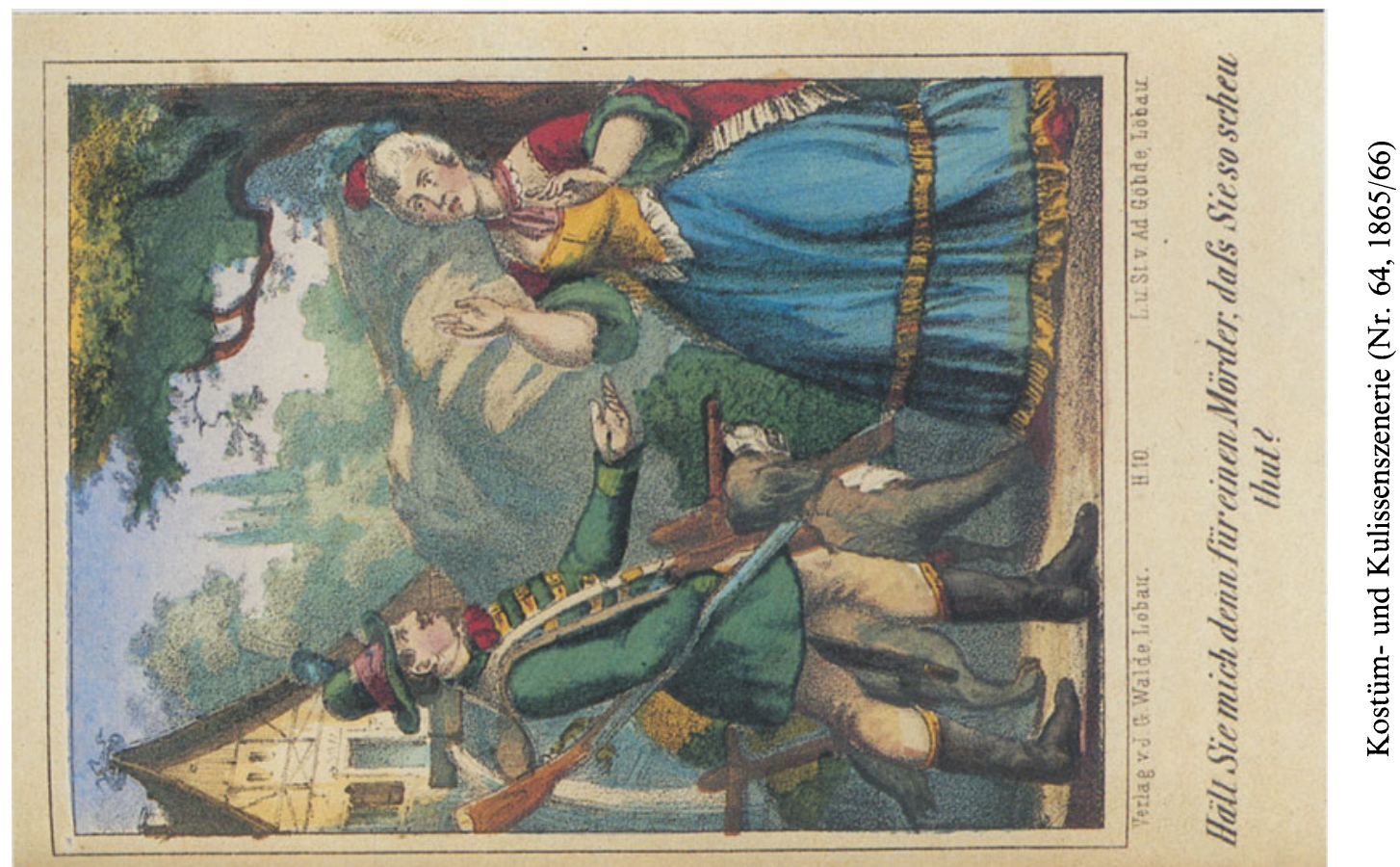

$\frac{1}{2}$
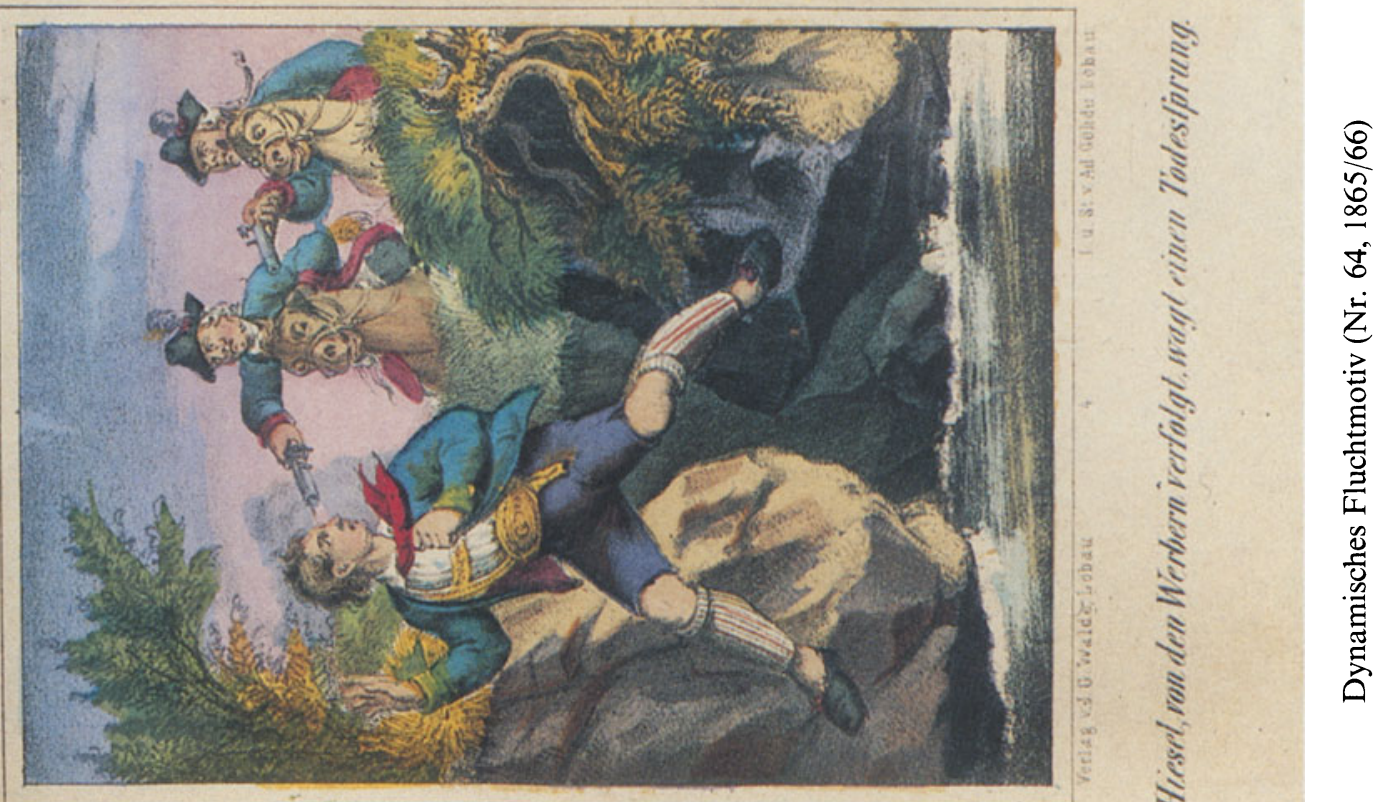

จ
$\frac{1}{7}$ 


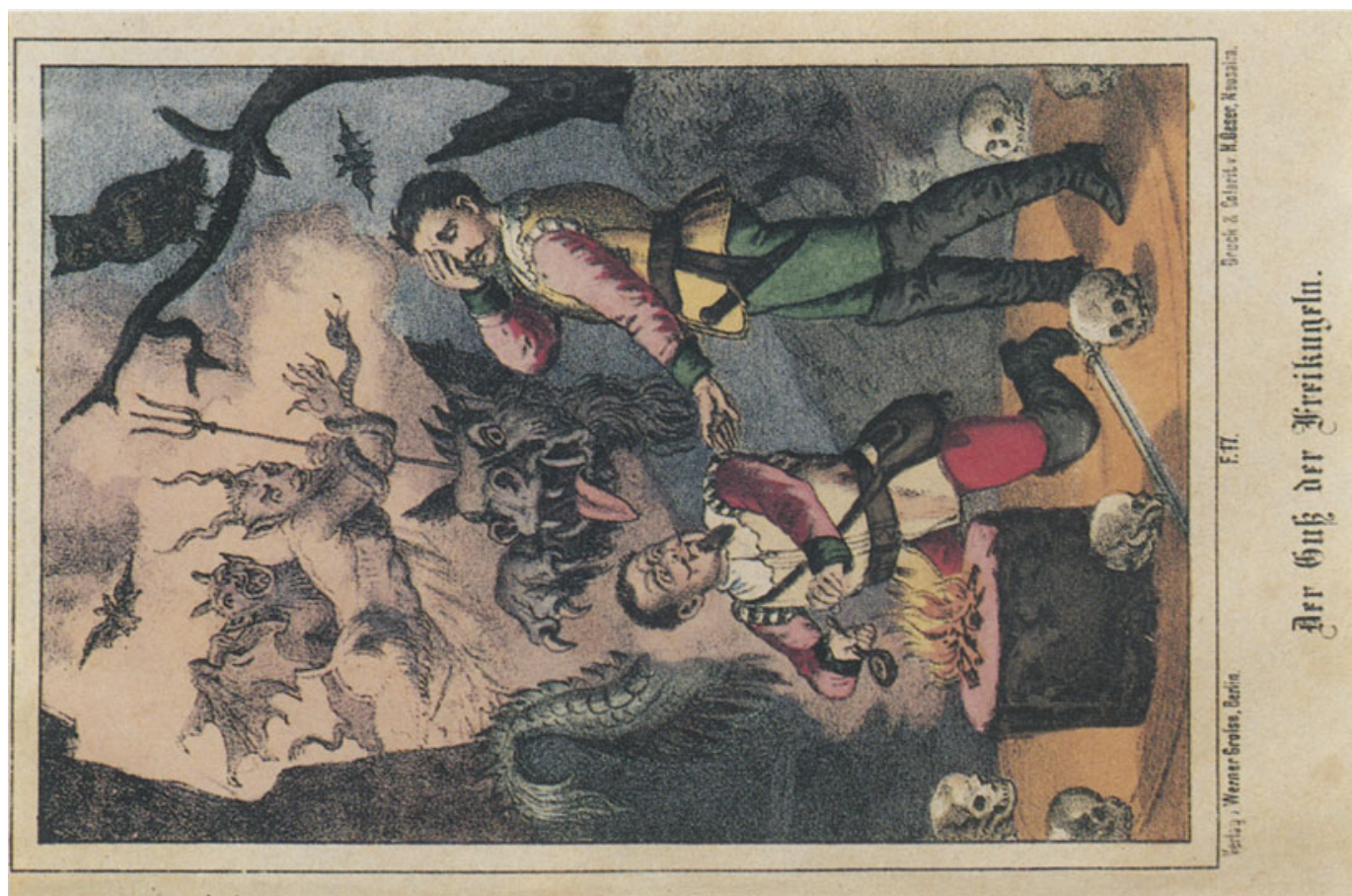

ฟึ่

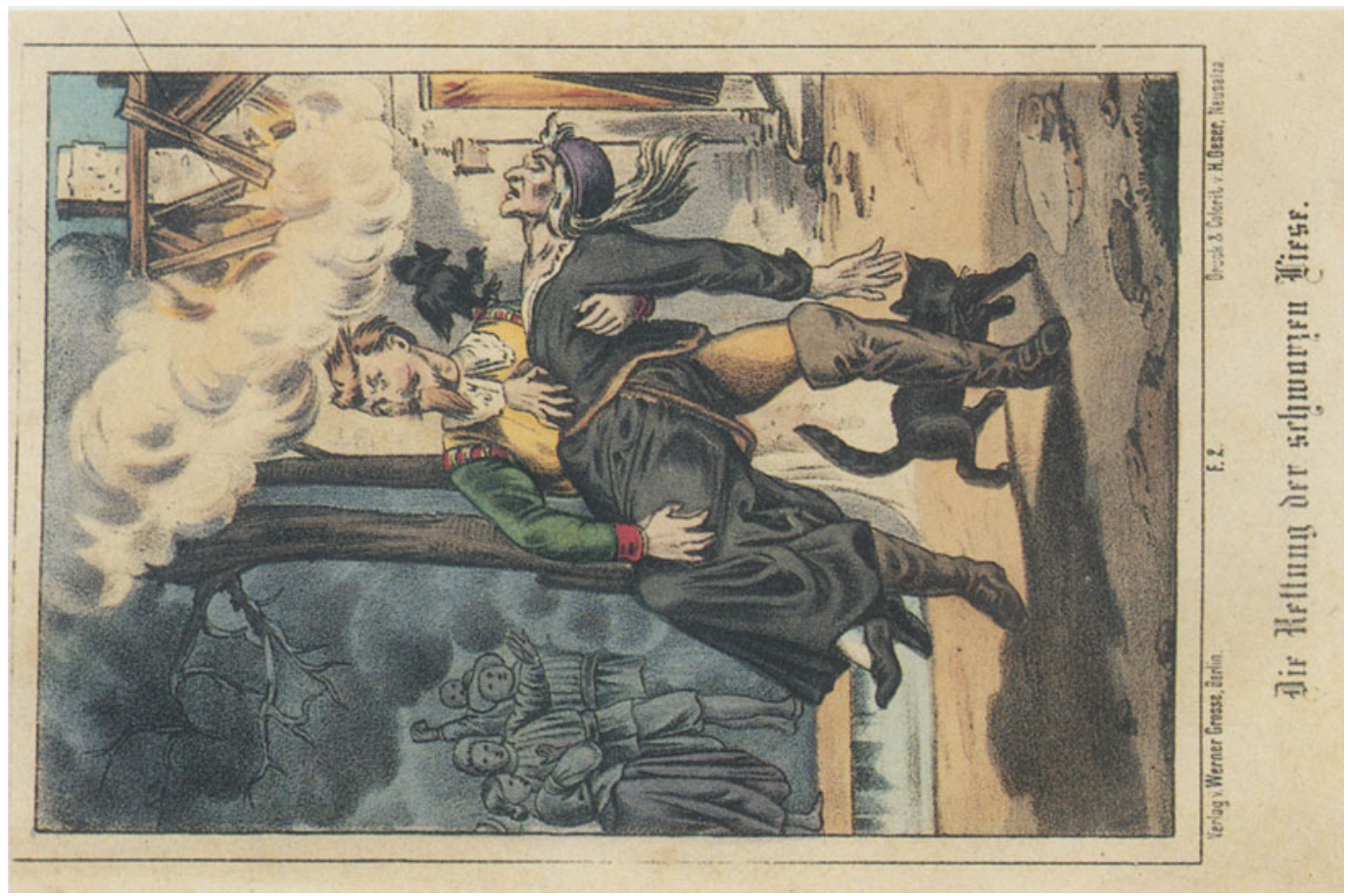

๙

₹ 

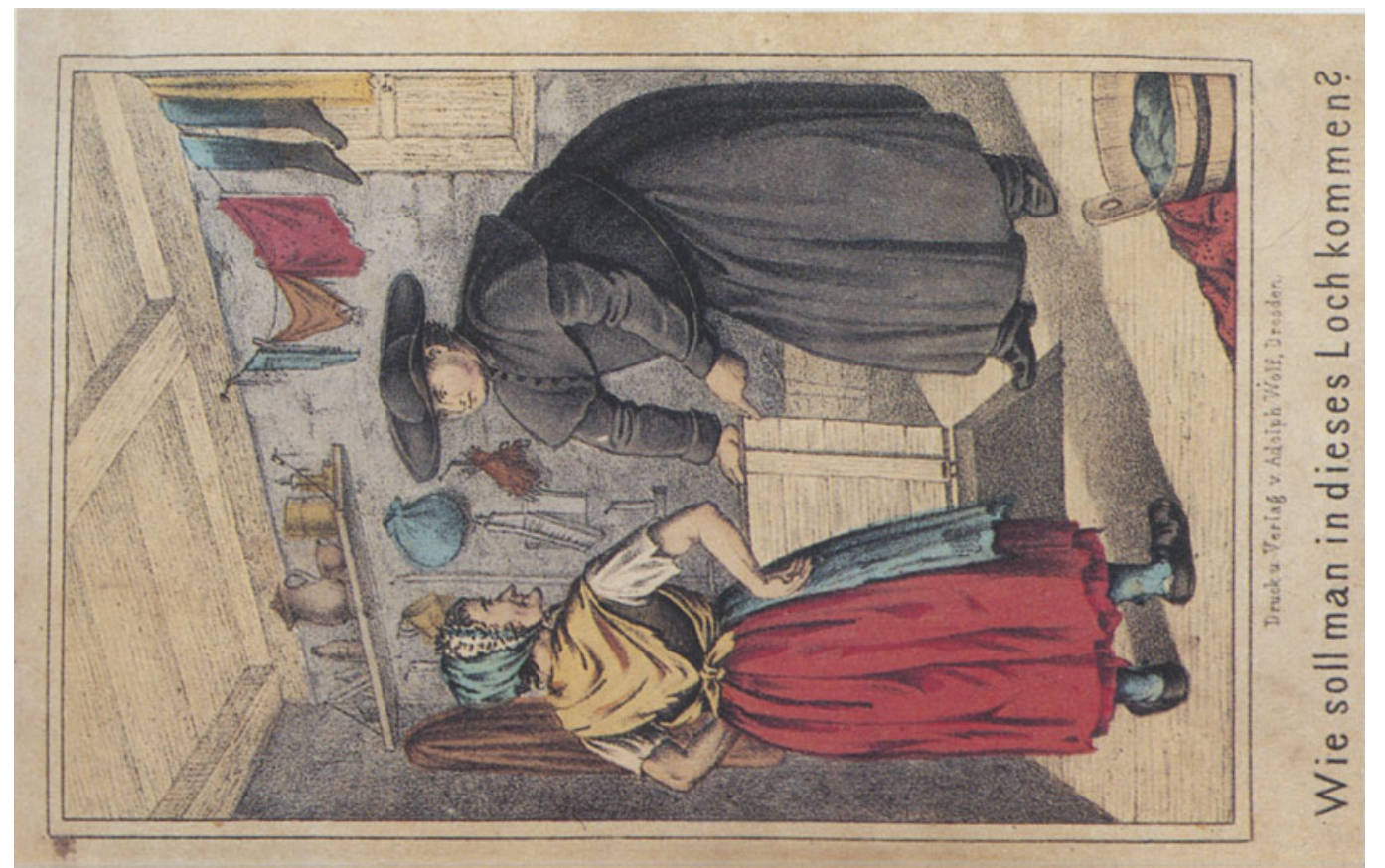

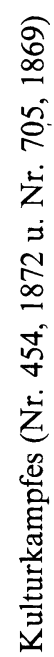
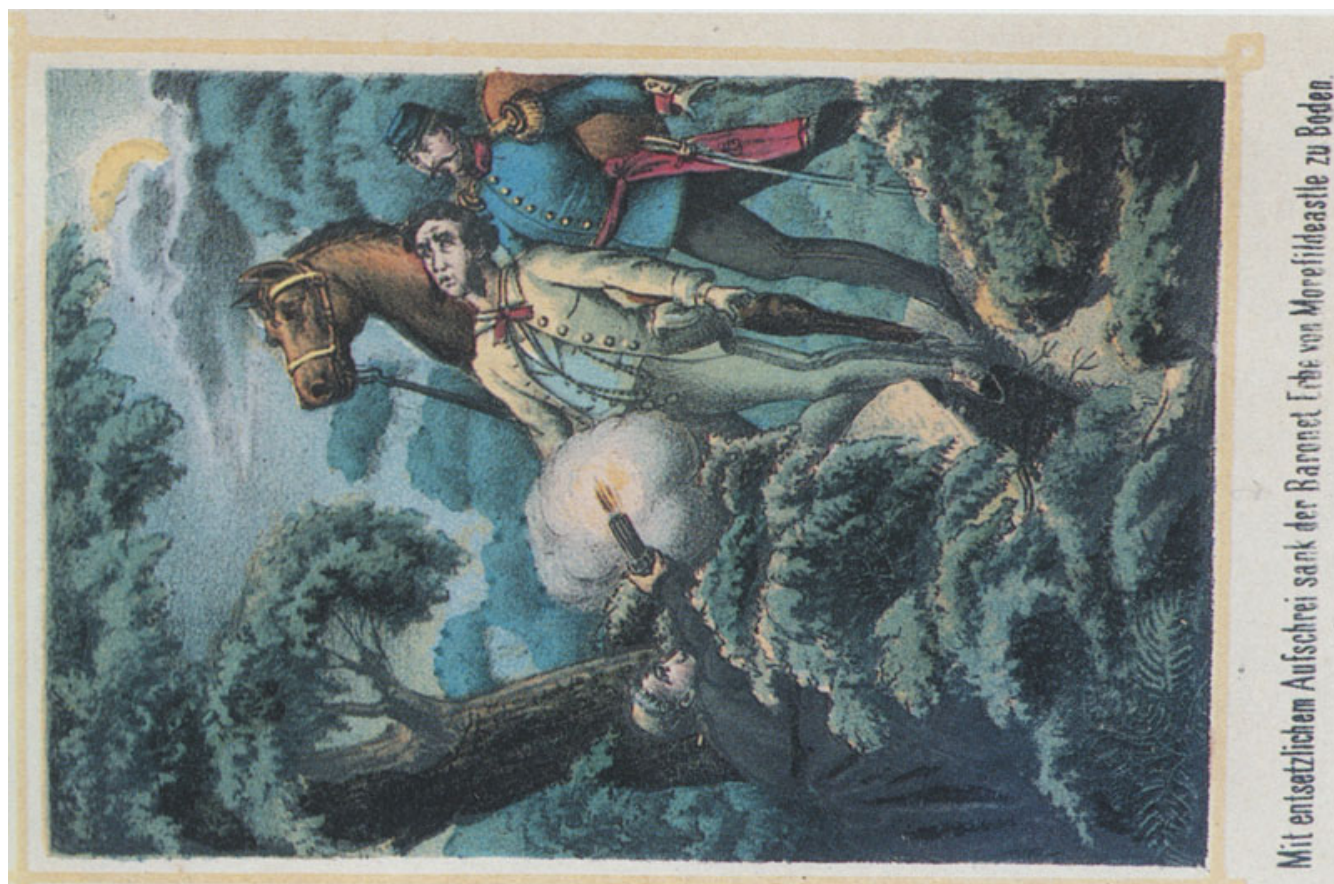

$\stackrel{\eta}{*}$
* 


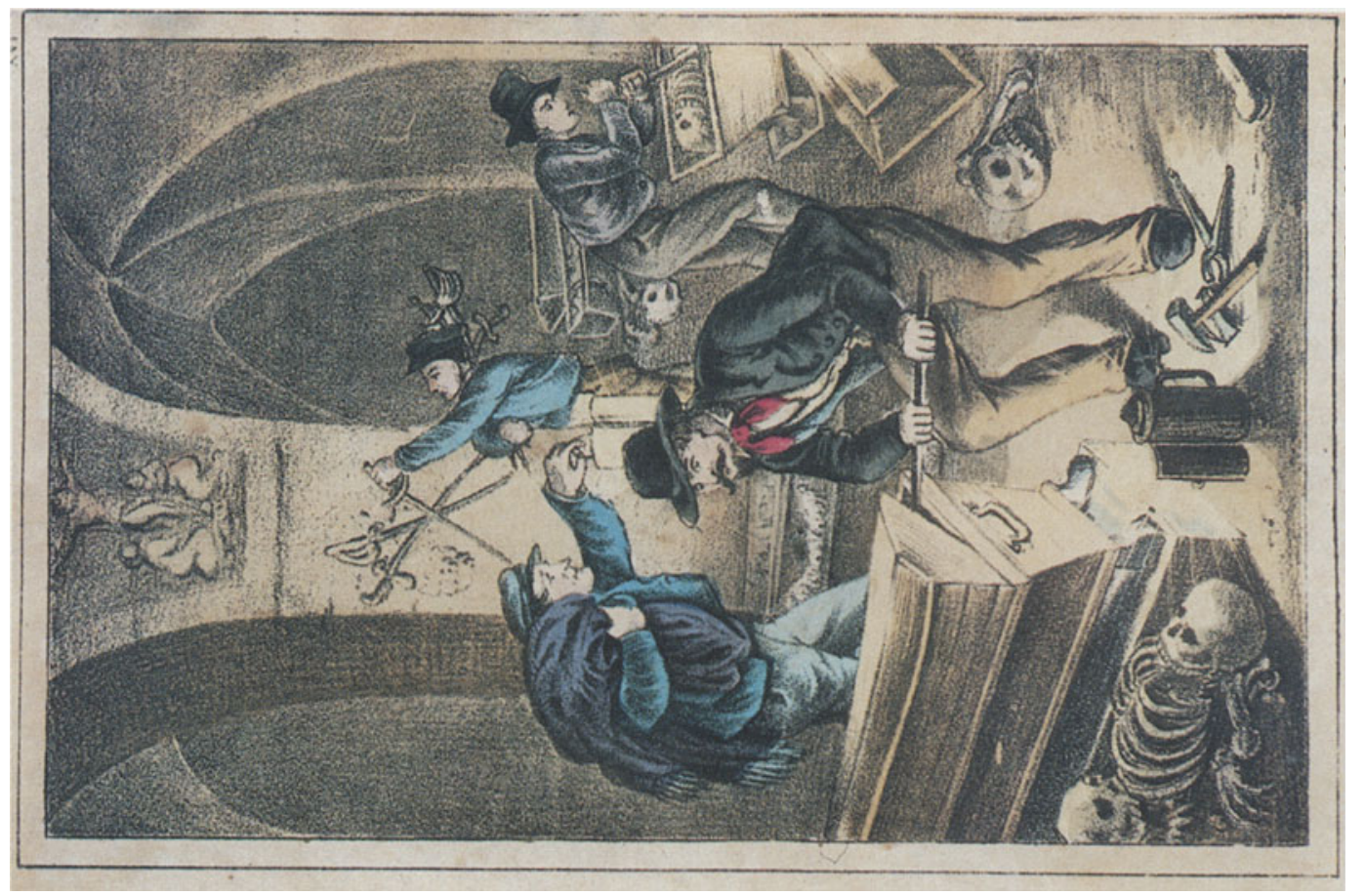

\begin{tabular}{l}
$m$ \\
\multirow{2}{*}{}
\end{tabular}

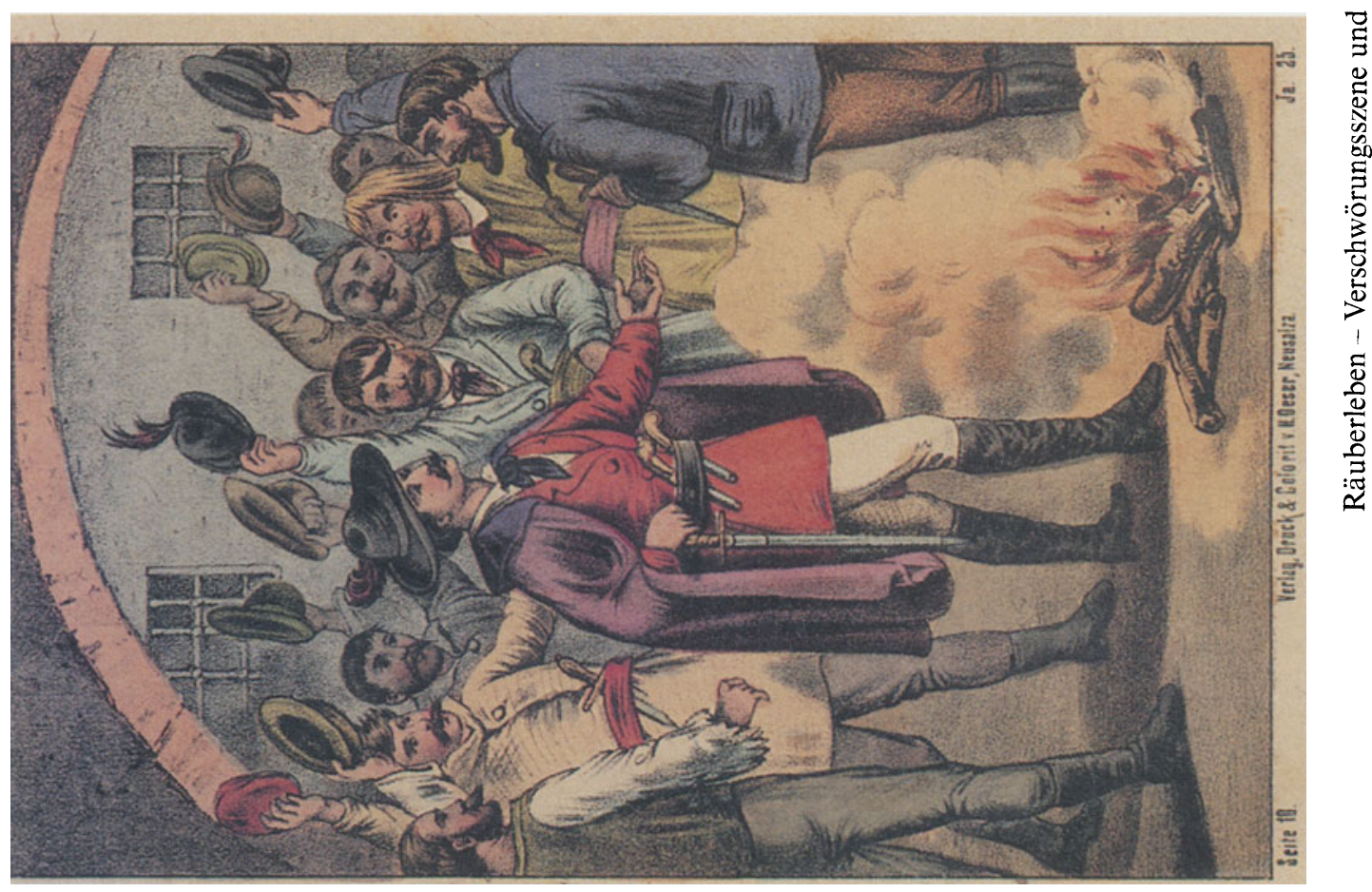

กี 


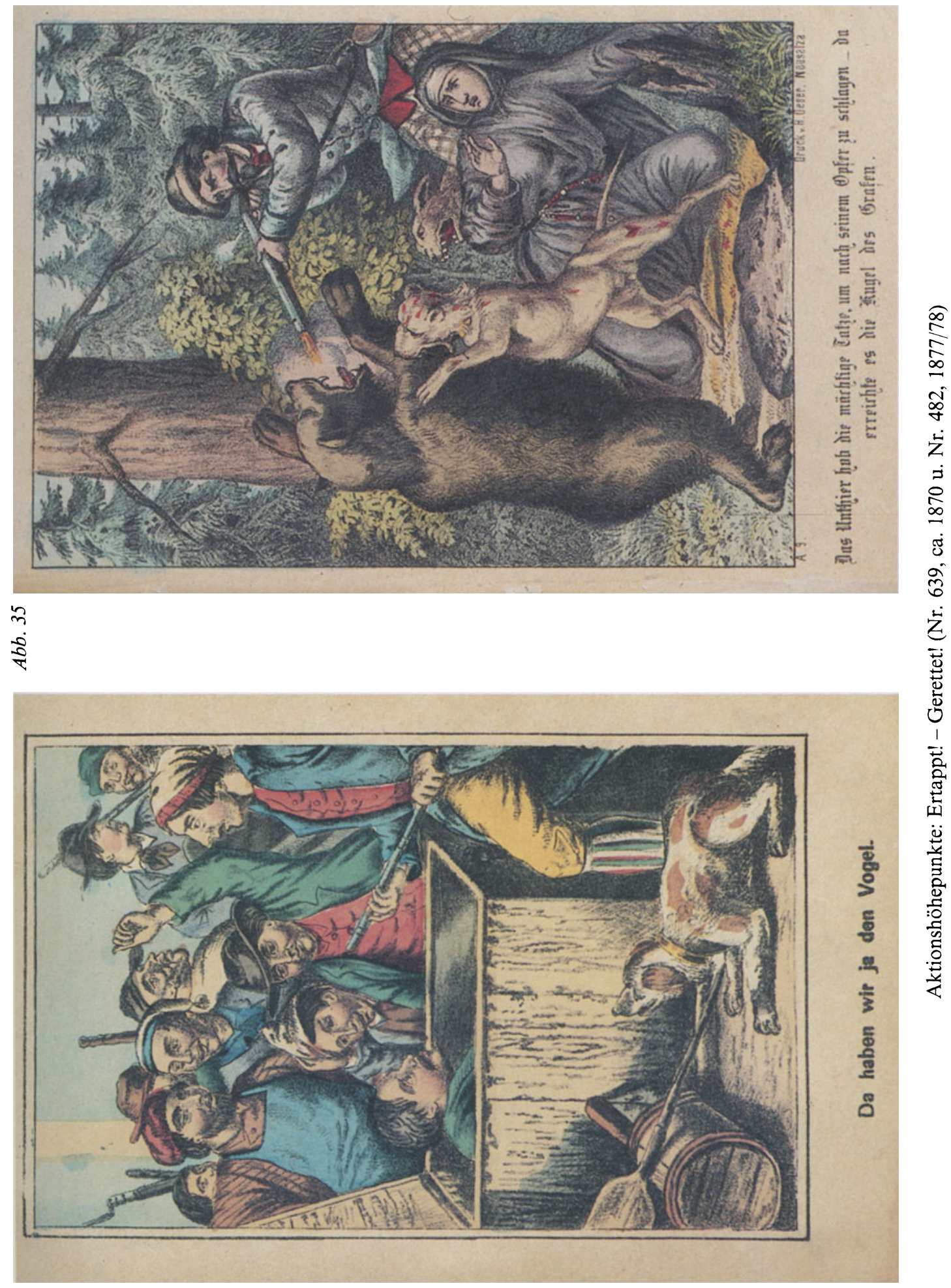

मे
के 


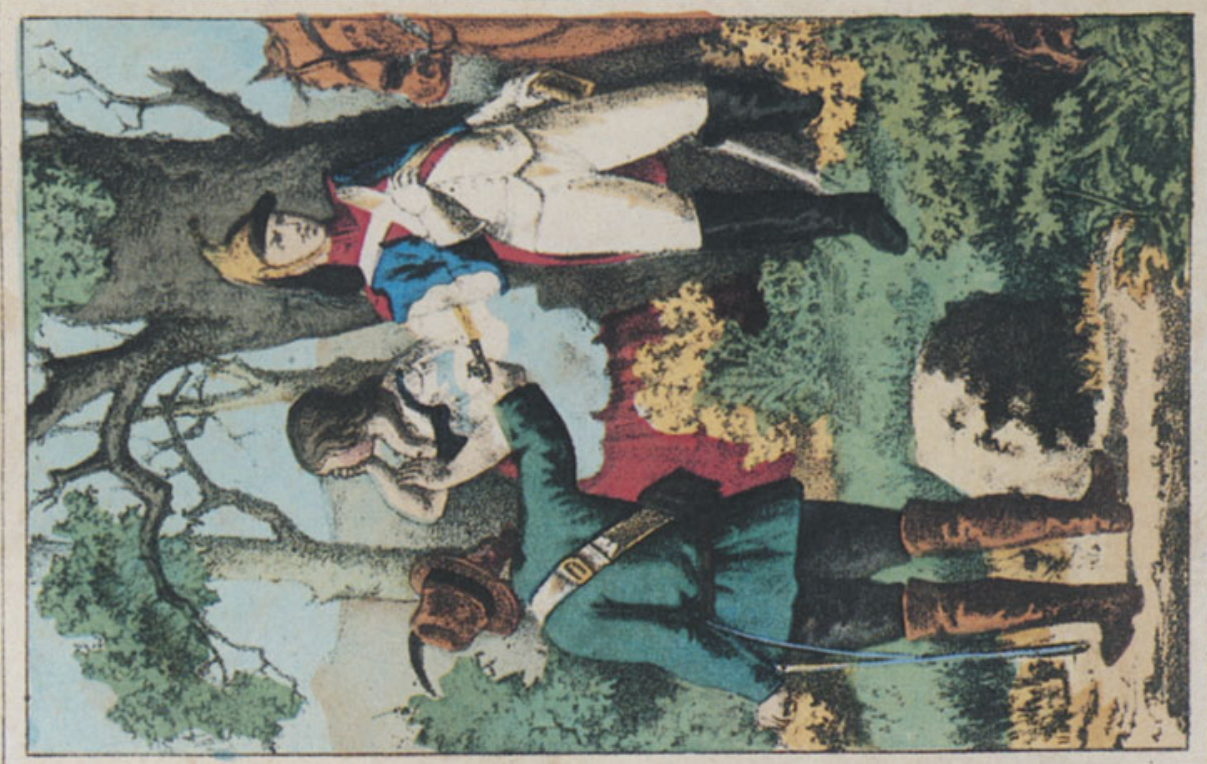

n

ह

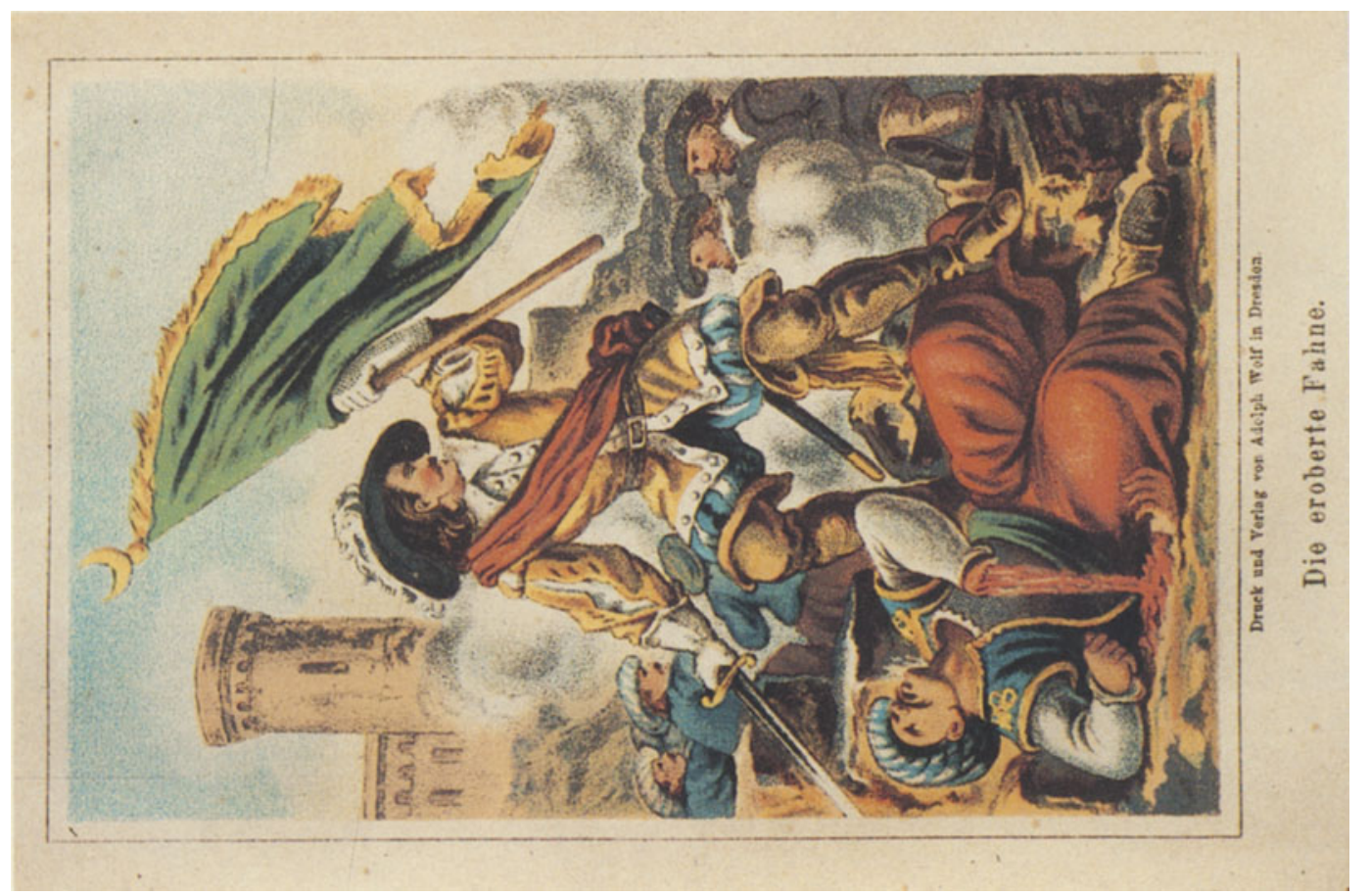

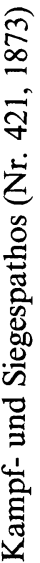

$i$
$\stackrel{7}{*}$ 


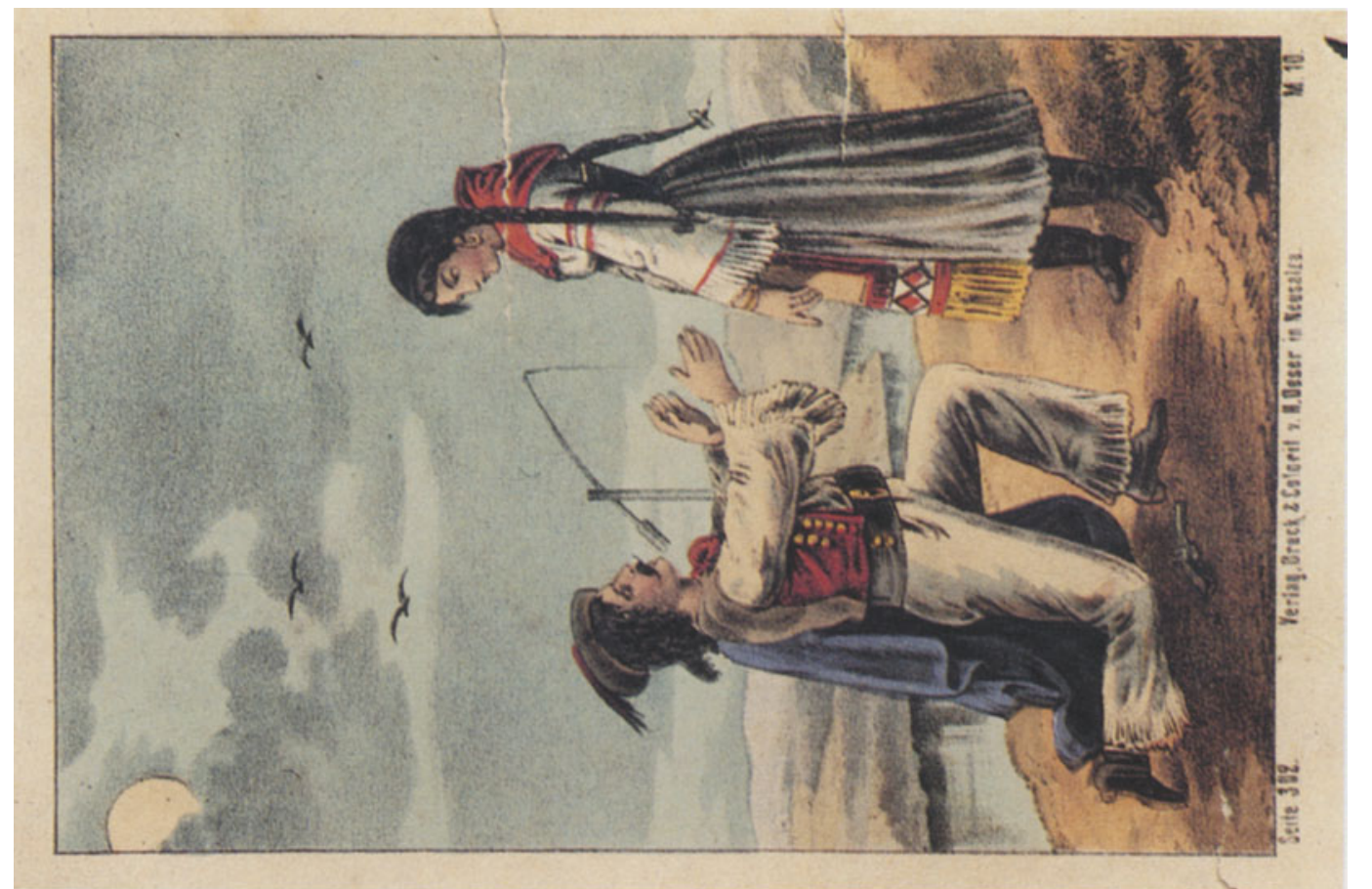

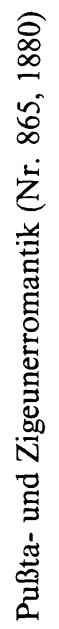

ก
₹

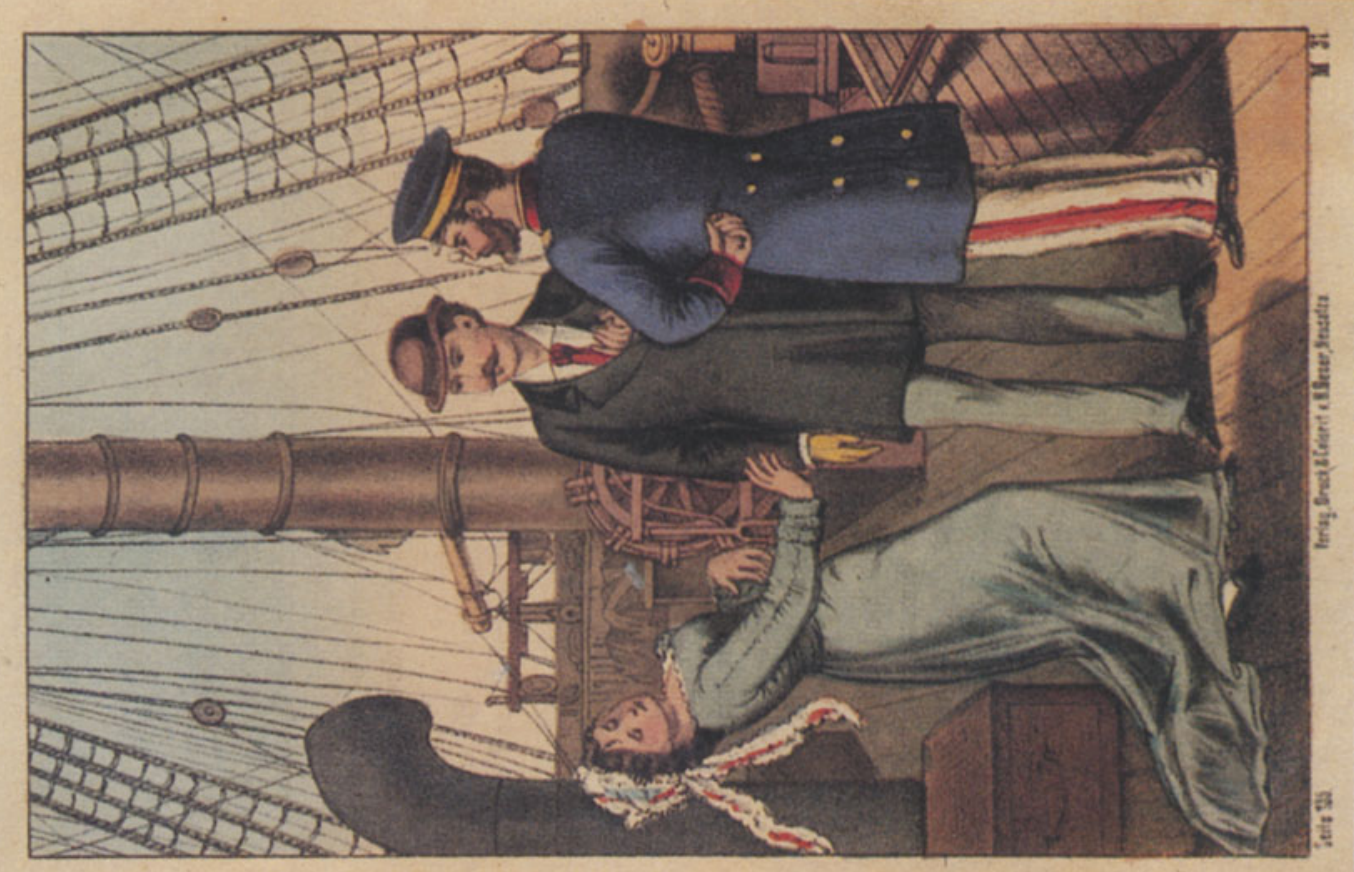

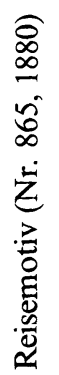

$\stackrel{\infty}{m}$ 


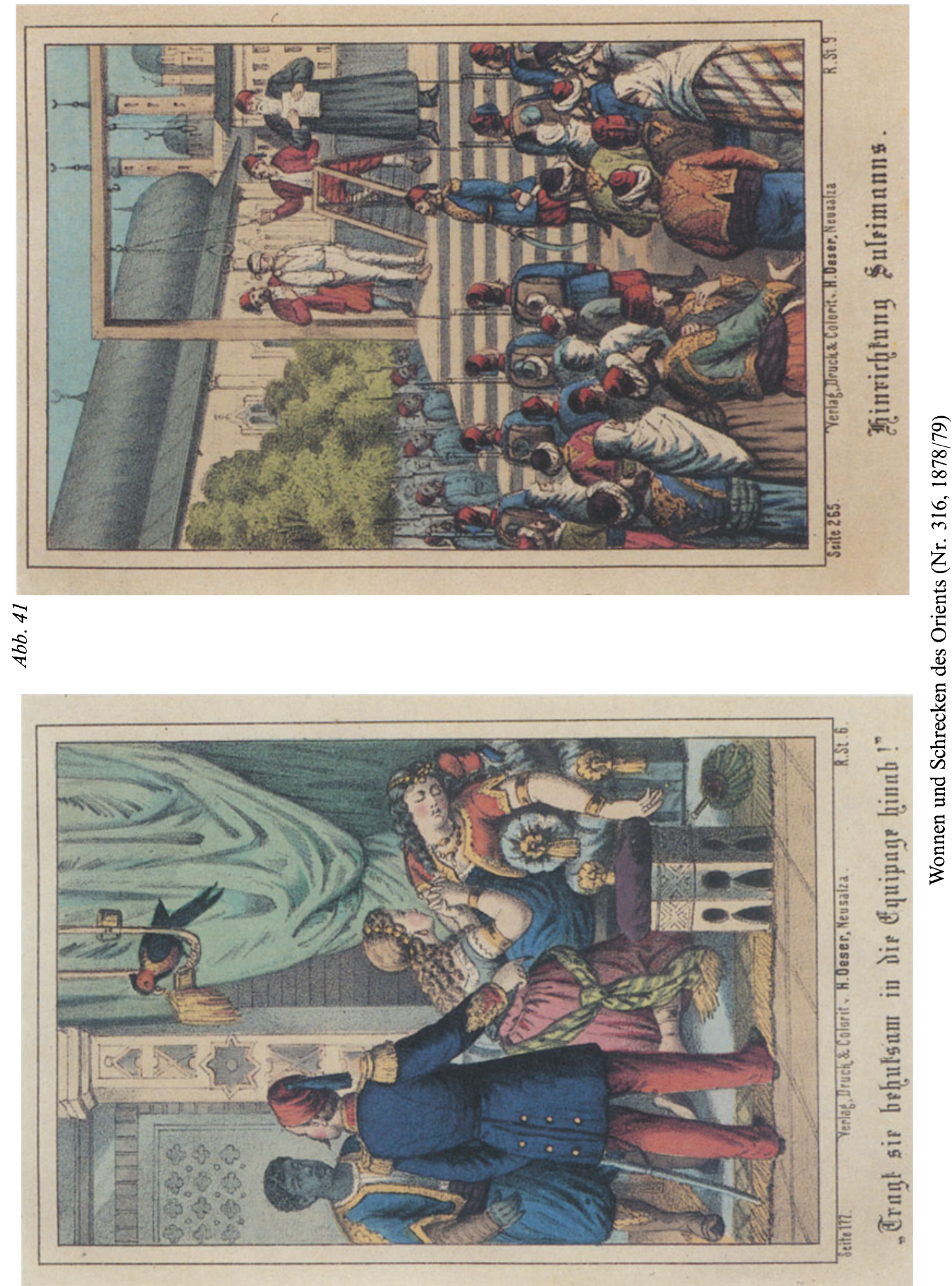

8
8
8 


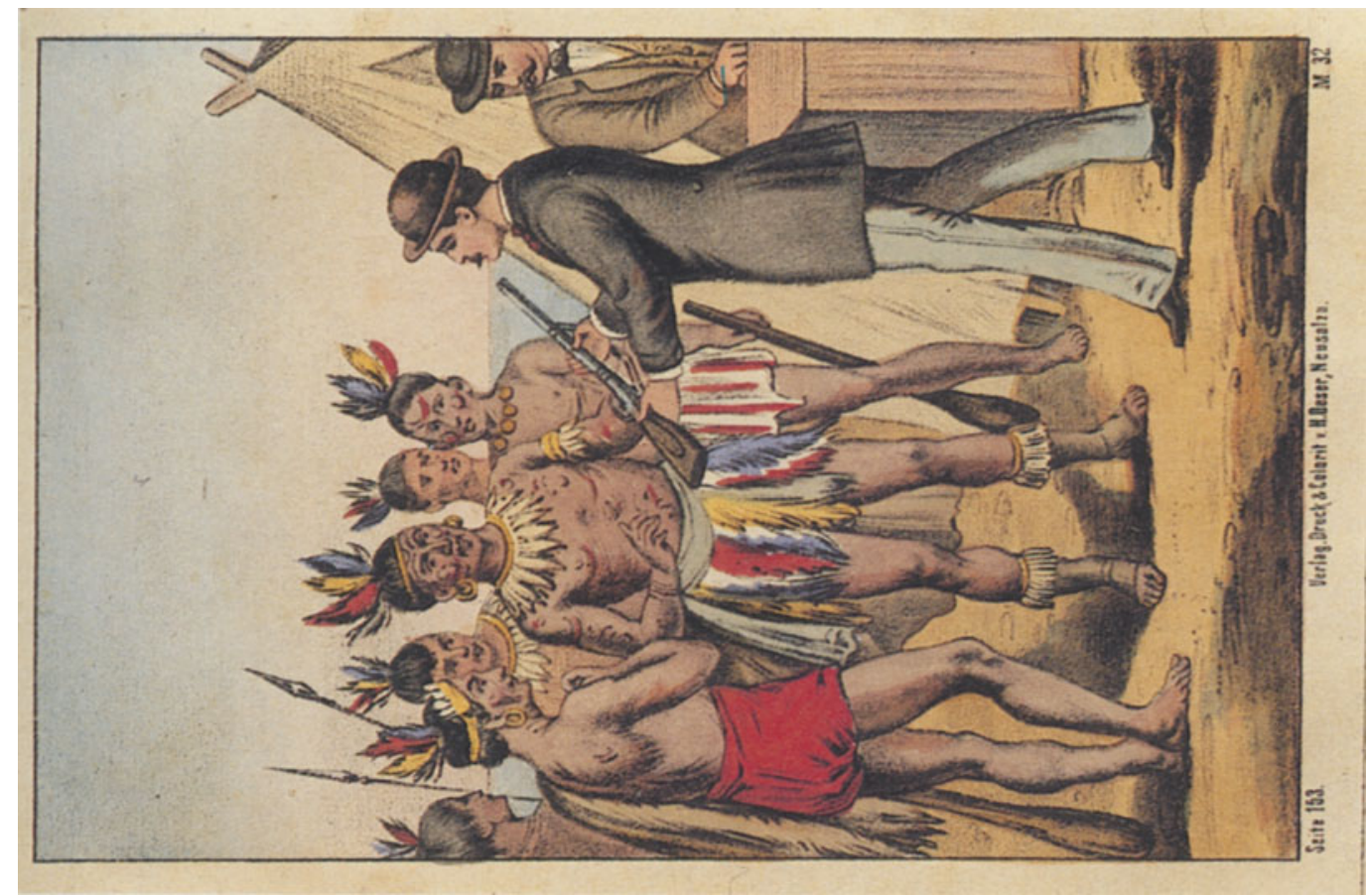

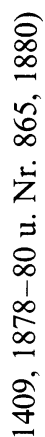

$\approx$

₹

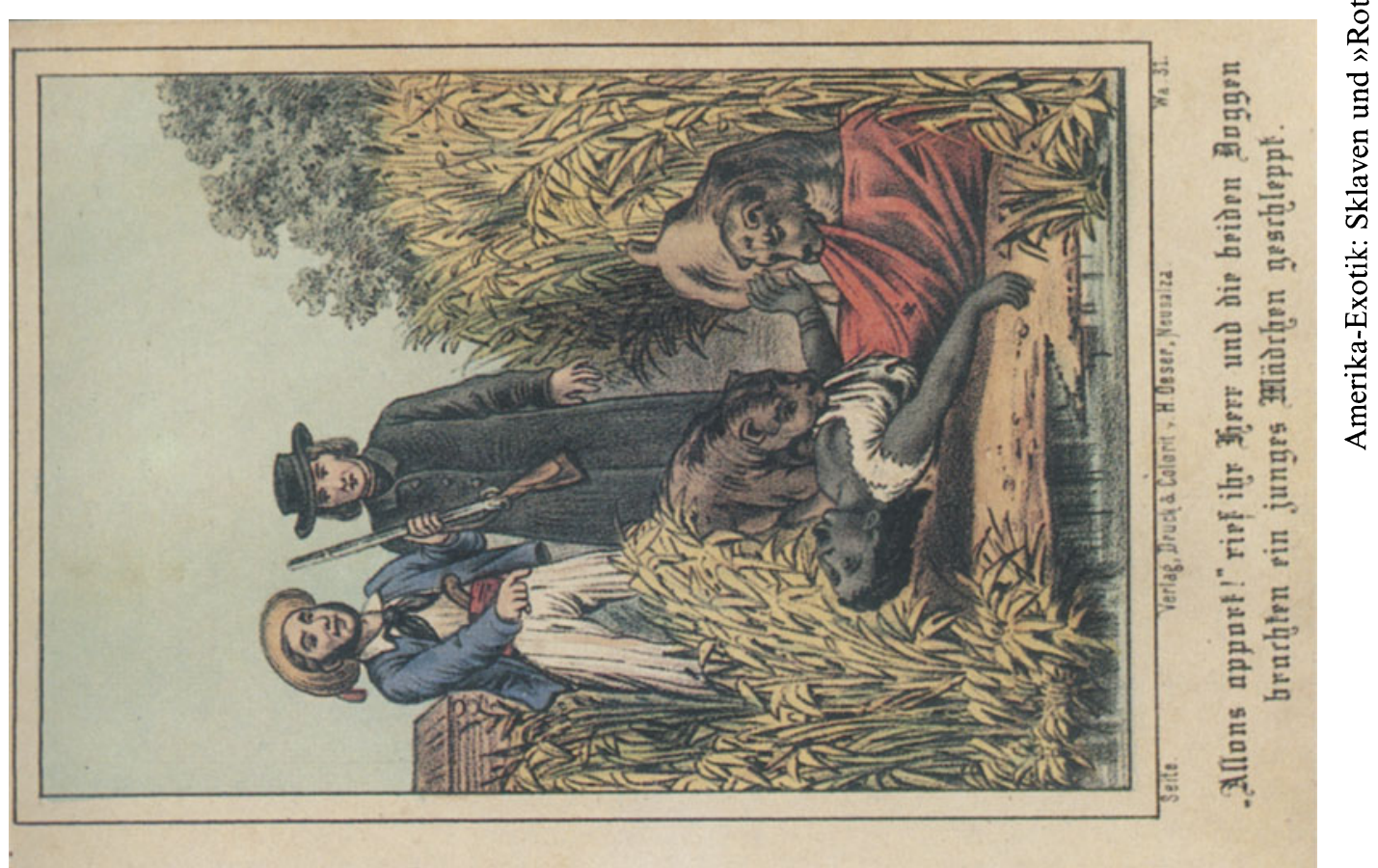

$\approx$
$\approx$ 


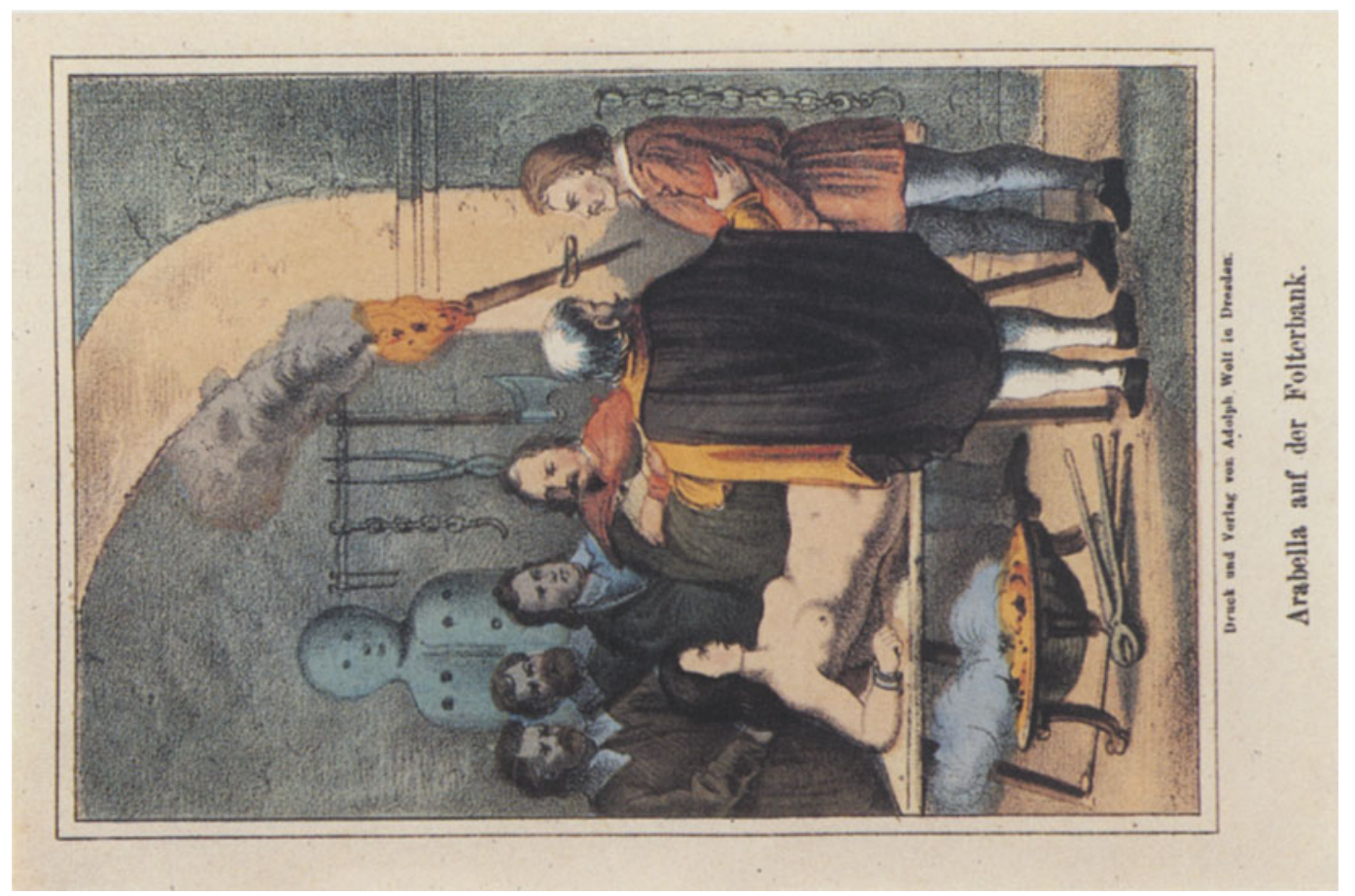

$n$
$\frac{7}{7}$

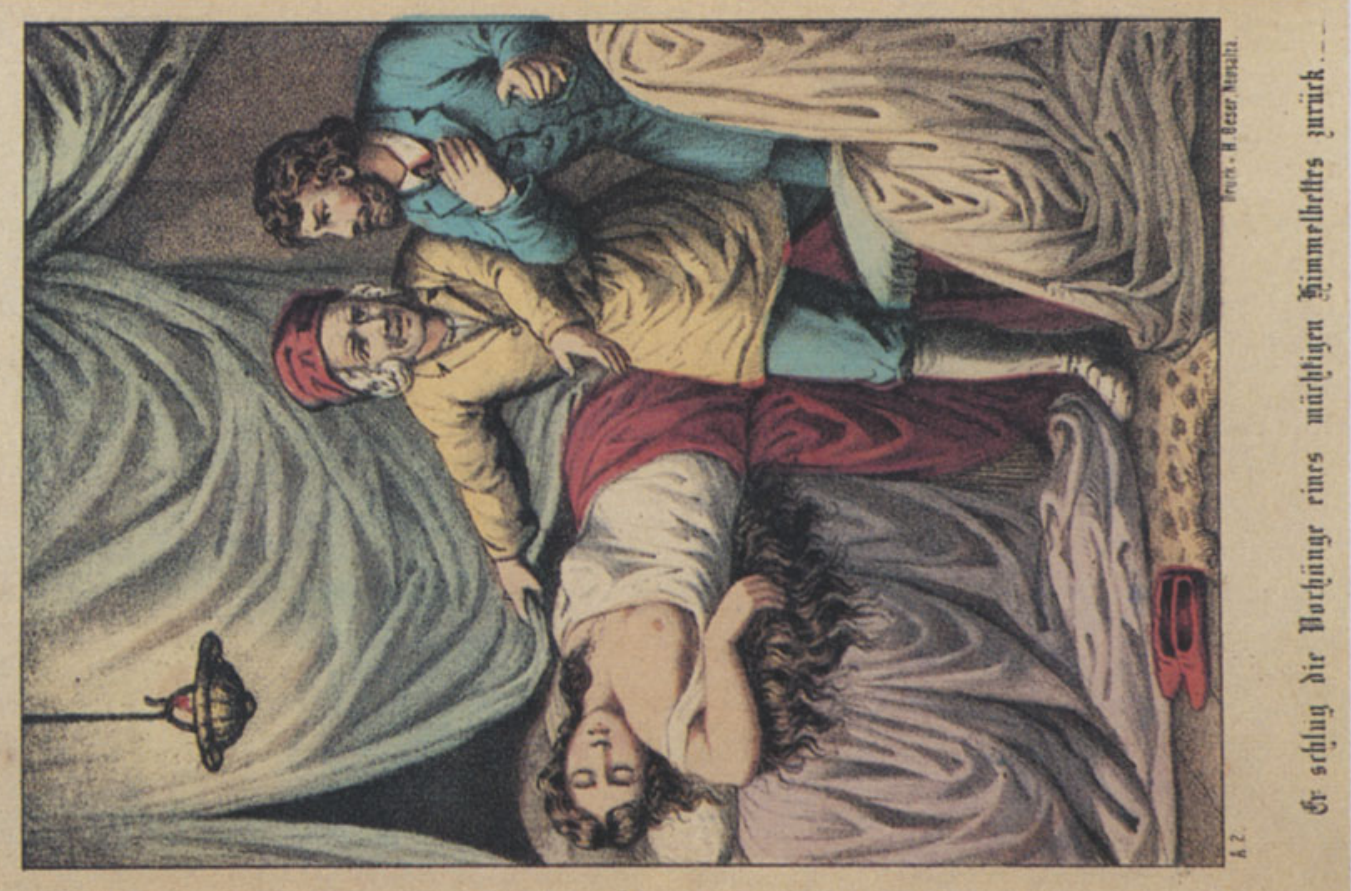

7
$\frac{7}{7}$ 


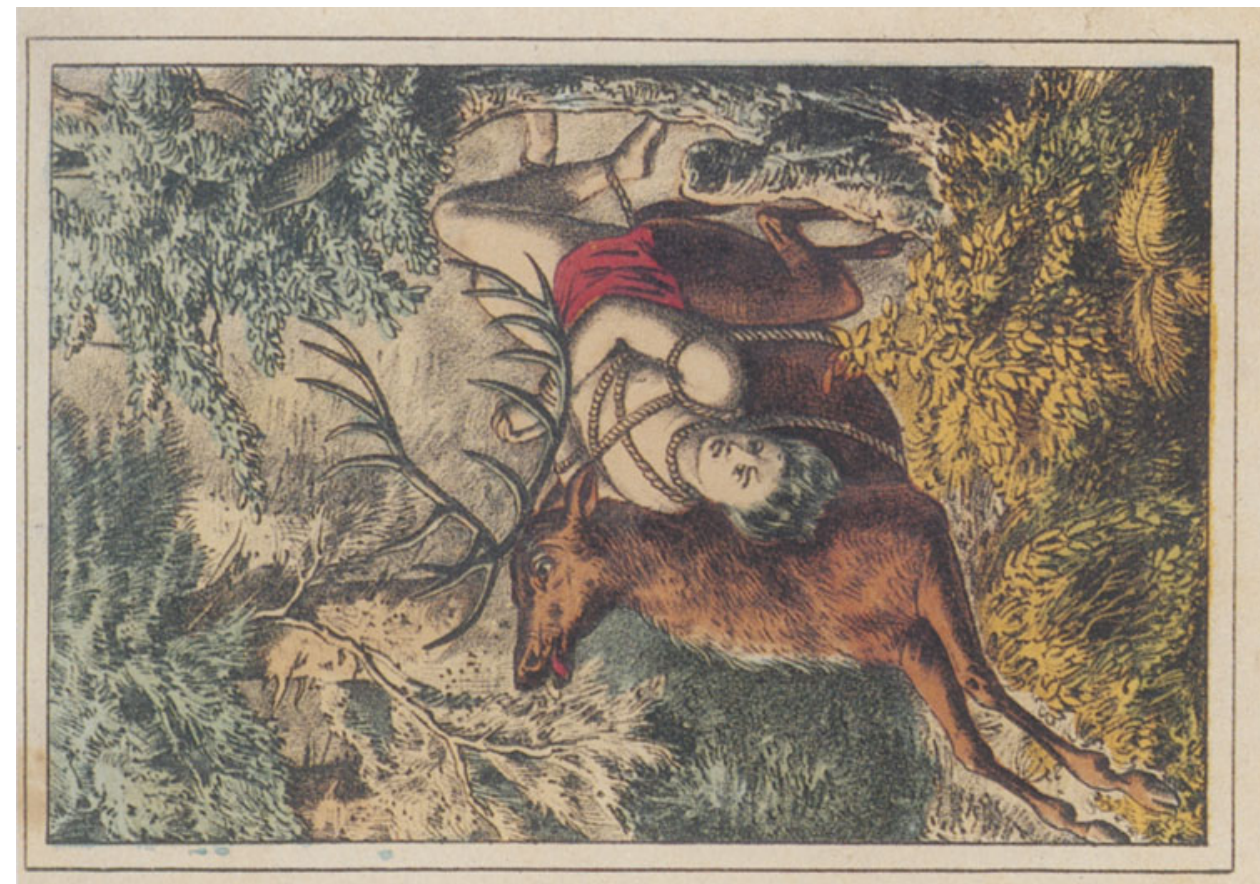

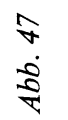
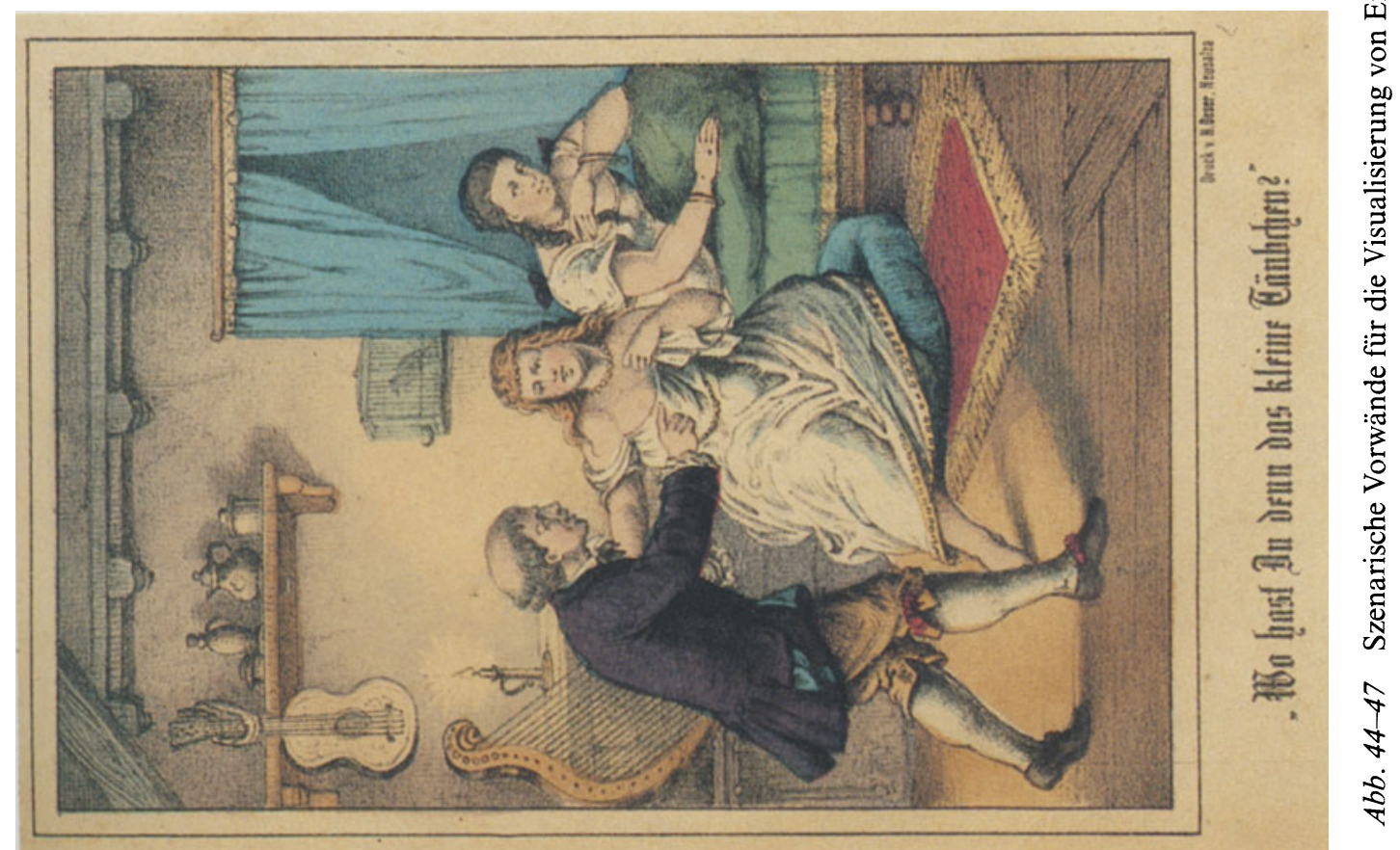

8
8
8 


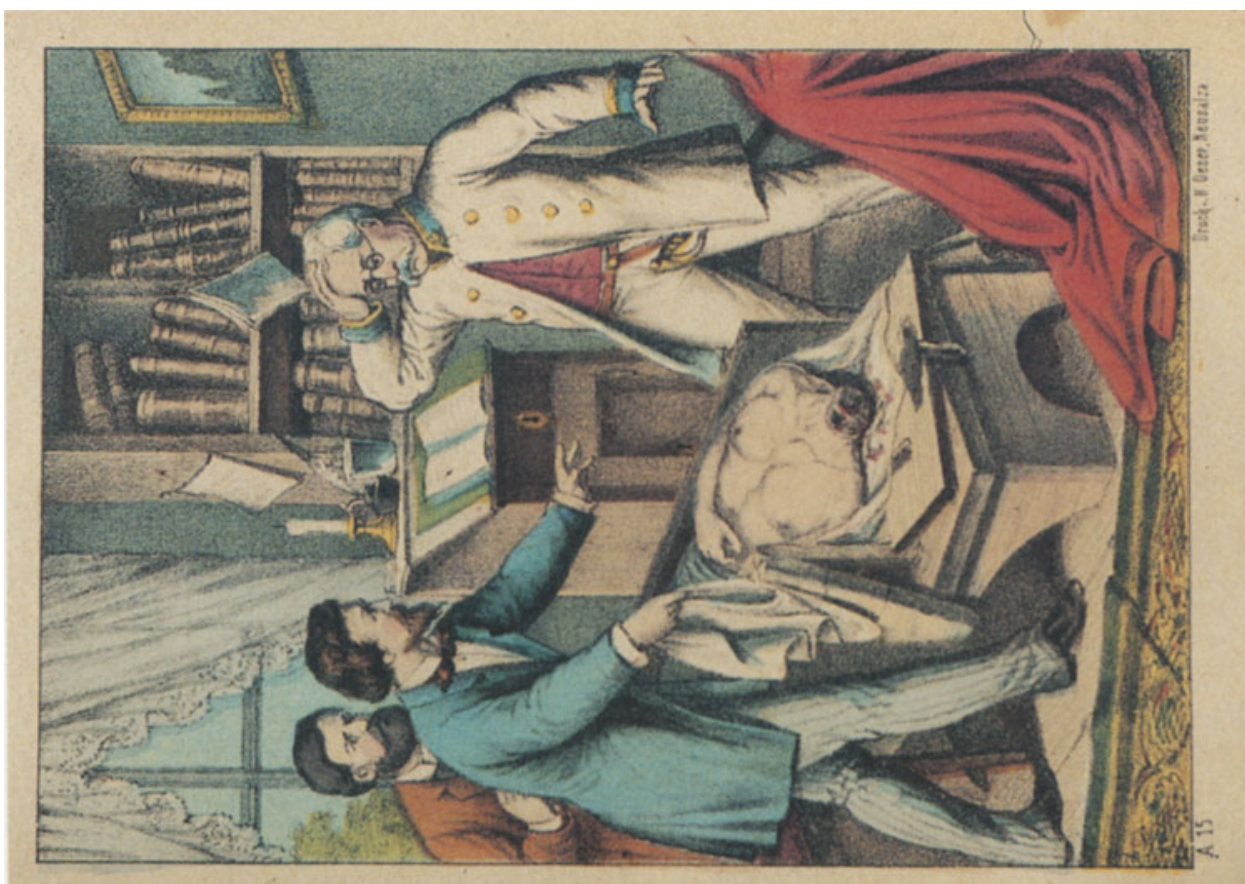

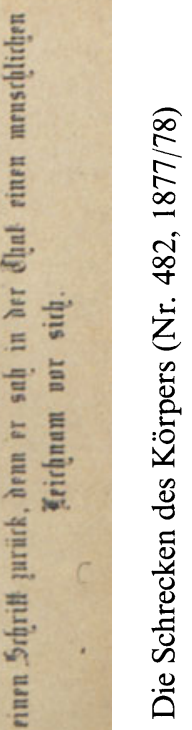

아

웅

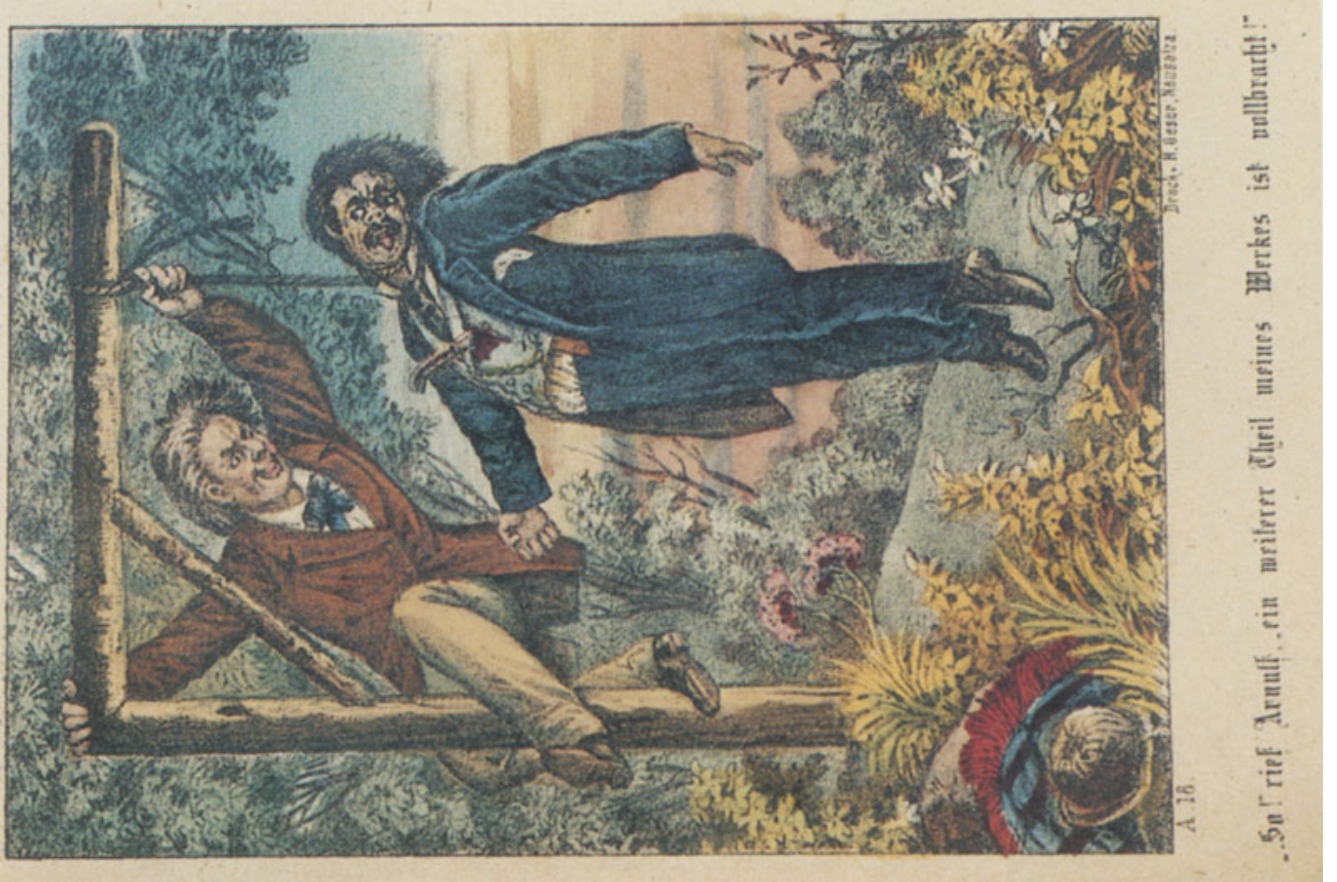




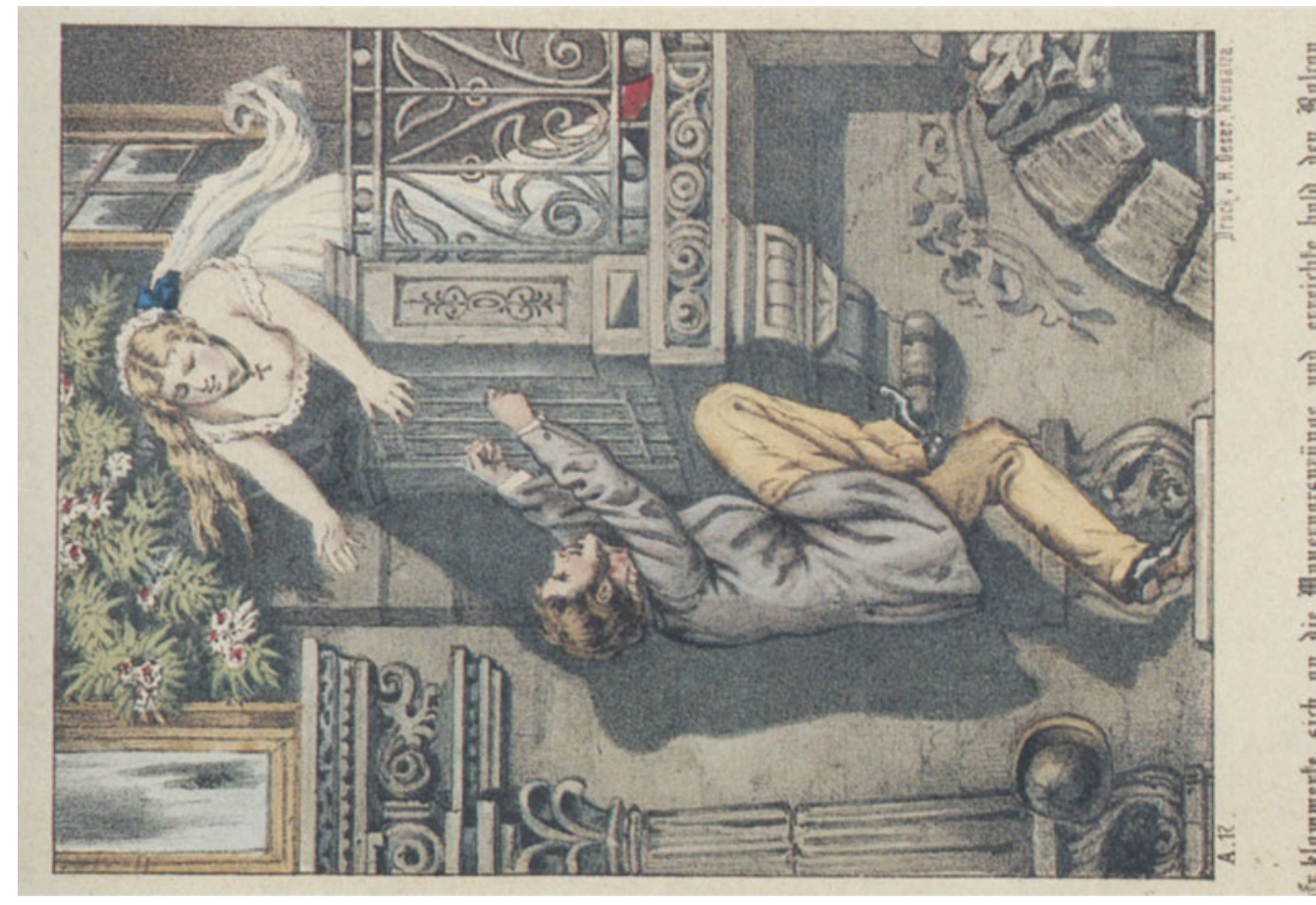

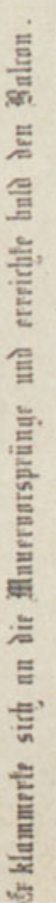

5
$\frac{1}{7}$

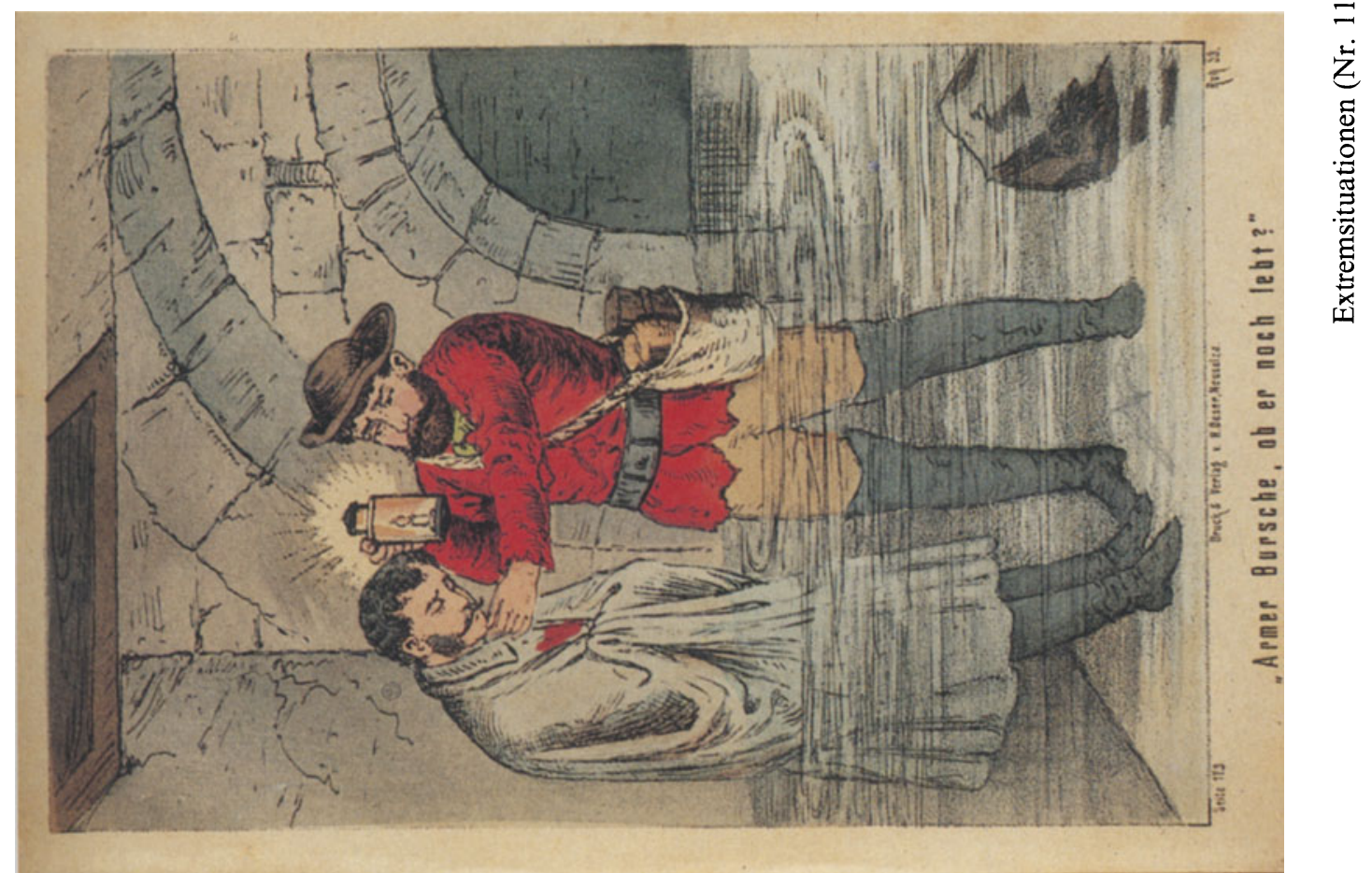

ำ 
Rr. 3. VII. Jabrgang.

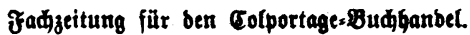

10. Februar 1891. 33

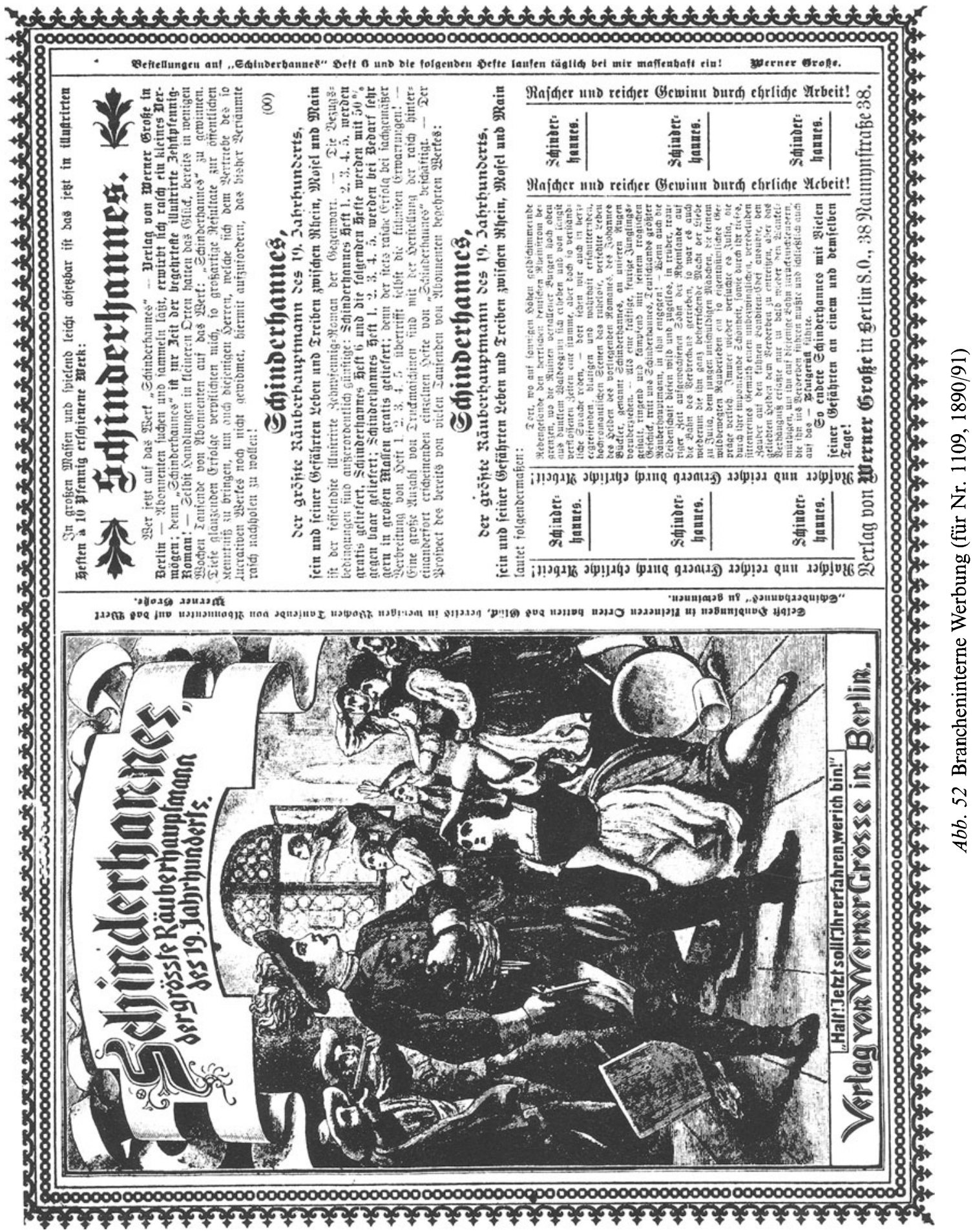

